\title{
UK Renal Registry 11th Annual Report (December 2008): Chapter 14 UK Renal Registry and international comparisons
}

\author{
Preetham Boddana ${ }^{a}$, Fergus Caskey ${ }^{a}$, Anna Casula ${ }^{b}$ and David Ansell ${ }^{b}$

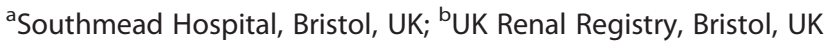

\section{Key Words}

Cardiovascular risk factors - Epidemiology - International comparison $\cdot$ Renal Registry

\begin{abstract}
Background: The aim of this study is to report Renal Replacement Therapy (RRT) incidence and prevalence rates, the percentage of incident patients with diabetes mellitus as cause of renal disease, the RRT modality mix and the transplant rate in different countries. The number of national or regional registries collecting and reporting data pertaining to traditional cardiovascular (CV) risk factors in prevalent dialysis patients is also examined. Methods: Data on numbers of incident and prevalent RRT patients in England, Wales, Scotland and Northern Ireland for the year 2007 were collected from the UK Renal Registry (UKRR) database and collated to meet the specifications on the US Renal Data System (USRDS) international data collection form. Results: In 2007, the incidence and prevalence of RRT in the UK were 110 and 759 per million of the population (pmp) respectively. Incidence of RRT placed the UK 34th out of the 43 countries reporting to the USRDS in 2006. In the majority of reporting countries, $20-44 \%$ have diabetes as the primary cause of end stage renal disease. Only the Finnish, Malaysian and US Renal Registries were found to routinely report attainment of cardiovascular risk standards. Conclusions: A comparison among international renal registries about RRT epidemiology
\end{abstract}

and reporting cardiovascular risk factors in prevalent RRT patients forms an important part of the quality improvement process and often allows for improving standards and performances between reporting countries. Despite the high CV morbidity associated with RRT, few renal registries routinely report data on CV risk management; where data are reported there is little agreement in what represents quality of care, making direct comparison difficult.

\section{Introduction}

Globally the number of patients on renal replacement therapy (RRT) with stage 5 chronic kidney disease (CKD) continued to increase. The number of countries with renal registries monitoring these patients, is also increasing. International comparisons of RRT epidemiology allow incidence rates, prevalence rates and transplantation rates to be compared across health care systems. The observed variability in provision, has generated hypotheses for studies to improve understanding of what percentage of the variation was related to either medical or health care organisational differences $[1,2,3]$.

The association between CKD and cardiovascular $(\mathrm{CV})$ risk factors, both traditional and non-traditional, has long been recognized [4]. CV risk factors have been

\section{KARGER \\ Fax +41613061234 E-Mail karger@karger.ch} www.karger.com
C 2009 S. Karger AG, Basel

$1160-2110 / 09 / 1115-0269 \$ 26.00 / 0$

Accessible online at: www.karger.com/nec
Preetham Boddana

UK Renal Registry, Southmead Hospital, Southmead Road, Bristol BS10 5NB, UK

Email: preetham.boddana@nbt.nhs.uk 
associated with progression of $\mathrm{CKD}$ and therefore may be expected to lead to higher rates of RRT. However, there was also the issue of competing risk, with CKD itself an independent predictor for $\mathrm{CV}$ disease and therefore also $\mathrm{CV}$ death prior to requiring RRT. Patients with stage 5 CKD were at high risk of CV morbidity and mortality [4], with rates in haemodialysis patients varying by age group from 2 (in older patients) to 20 times (in younger patients) higher than those of the general population of the same age [5]. These CV deaths accounted for 30$50 \%$ of all deaths on dialysis $[5,6]$. Considerable centrelevel variation has been demonstrated in attainment of standards for the traditional CV risk factors of blood pressure and cholesterol in the UK [7], but few other national registries routinely collected and reported such data.

The aims of these analyses are to present RRT incidence and prevalence rates for the four UK countries alongside those of a wide range of countries worldwide. Supplementary analyses aim to identify and summarise data from all national and international renal registries reporting attainment of standards data for traditional $\mathrm{CV}$ risk factors in relation to KDOQI guidelines for patients on RRT.

\section{Methodology}

\section{Epidemiology}

The data on incident and prevalent RRT patients in England, Wales, Scotland and Northern Ireland in 2007 were obtained from the UKRR database and collated to meet the specifications on the USRDS international data collection form. The numerators for incidence and prevalence were based on all incident and prevalent patients in England, Wales, Scotland and Northern Ireland and the general population data for the denominators were based on the entire populations of the four UK countries (obtained from the Office for National Statistics). In order to be consistent with the definitions used in the USRDS Report, a day 0 definition of RRT was used for RRT incidence rates. The UK rates quoted included an adjustment for paediatric patients 2 pmp has been added to the RRT incidence rate and $14 \mathrm{pmp}$ has been added to the RRT prevalence rate.

Data from tables in the USRDS annual data report 2008 were used to review the relative position of the UK countries in RRT incidence, prevalence, modality use and rates of transplantation compared with other international countries [8]. For the majority of countries included in the USRDS international comparison, data were for the year 2006; although for several countries, only data for earlier years were available.

Attainment of standards data

All national and regional renal registries were identified by reviewing international comparison chapters in renal registry
Table 14.1. Cardiovascular risk factors and relevant standards in the NKF KDOQI clinical practice guidelines

Clinical practice

Traditional cardiovascular risk factors guidelines

Target blood pressure for CVD reduction in $\mathrm{CKD}^{\mathrm{a}}$

Pre-dialysis blood pressure ${ }^{\mathrm{b}}$

Post-dialysis blood pressure ${ }^{\mathrm{b}}$

Target $\mathrm{HbA} 1 \mathrm{c}^{\mathrm{c}}$

$\mathrm{LDL}^{*}$ a

$<130 / 80 \mathrm{~mm} \mathrm{Hg}$

$<140 / 90 \mathrm{mmHg}$

$<130 / 80 \mathrm{mmHg}$

$<7.0 \%$

$<100 \mathrm{mg} / \mathrm{dl}$

$(<2.59 \mathrm{mmol} / \mathrm{L})$

Treatment decisions for dyslipidemia in NKF-KDOQI guidelines and the Adult Treatment Panel III are based on levels of triglycerides, LDL, and non-HDL cholesterol.

${ }^{\text {a }}$ Moderate evidence that the practice improves net health outcomes

${ }^{\mathrm{b}}$ Weak evidence that the practice improves net health outcomes

${ }^{c}$ Strong evidence that the practice improves net health outcomes

*Adults with stage $5 \mathrm{CKD}$

annual data reports and following links from the UKRR, European Renal Association (ERA-EDTA) and USRDS website links pages. Where other international registries had websites, these were visited and any reporting of traditional CV risk factors (hypertension, diabetes and dyslipidaemia) were identified.

Data on these CV risk factors for England, Wales and Northern Ireland were obtained from the UKRR database. In the absence of internationally agreed standards for CV risk factors in dialysis patients, the relevant standards in the National Kidney Federation's KDOQI clinical practice guidelines were adopted as the target for optimal management (table 14.1) [9-11].

\section{Results}

\section{Incidence of RRT}

In 2007, the incidence of RRT in the UK was $111 \mathrm{pmp}$ (figure 14.1). This rate placed the UK 34th out of the 43 countries reporting incidence data to the USRDS for 2006. However, the overall RRT incidence reported for the UK masked a higher rate of $142 \mathrm{pmp}$ in Wales, when compared with 110, 109 and 107 respectively in Scotland, England and Northern Ireland.

The percentage of incident RRT patients with diabetes recorded as the primary renal diagnosis was relatively low in the UK at $20 \%$, when compared with rates of over $40 \%$ in 9 out of the 36 countries that were able to report these data to the USRDS. Malaysia had the highest rate of diabetes as the primary renal diagnosis at 58\% in 2006 (figure 14.2). Within the UK, Wales had the highest percentage at $34 \%$ of incident RRT patients with diabetes recorded as the cause of their renal disease, followed by 


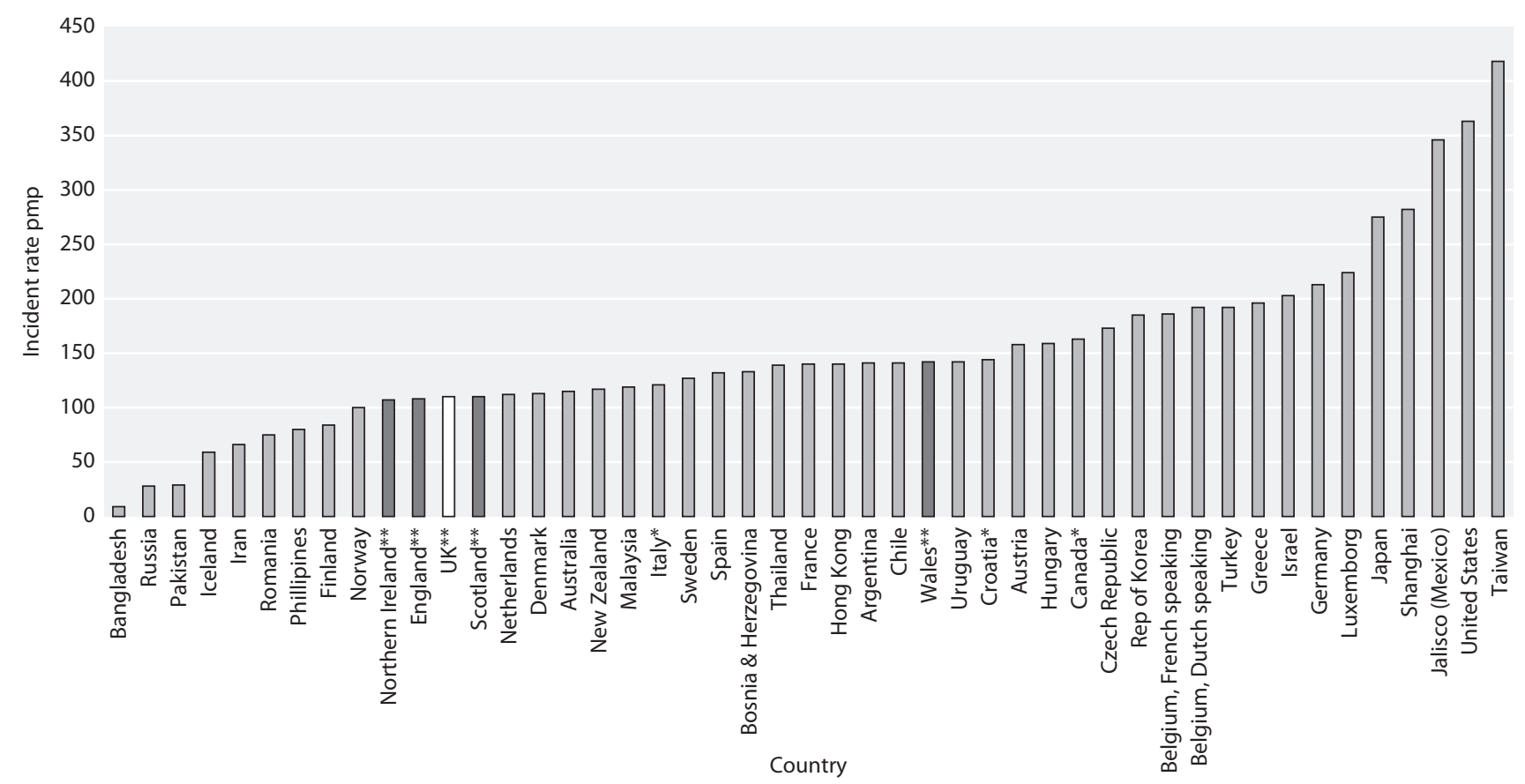

Fig 14.1. Incidence of RRT in different countries (pmp) *2005 data

**2007 data

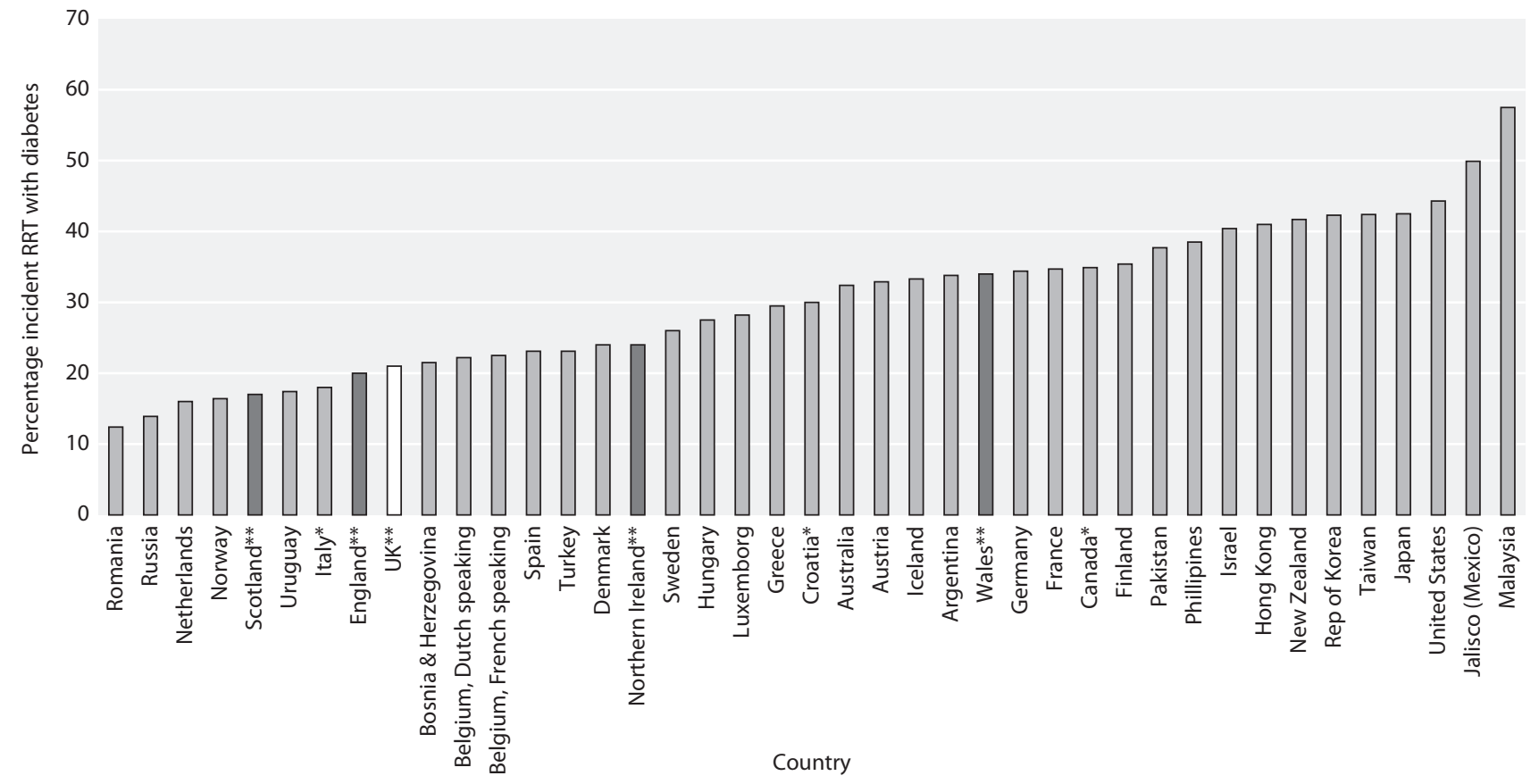

Fig. 14.2. Percentage of incident RRT population with diabetes mellitus as the primary renal diagnosis *2005 data **2007 data 


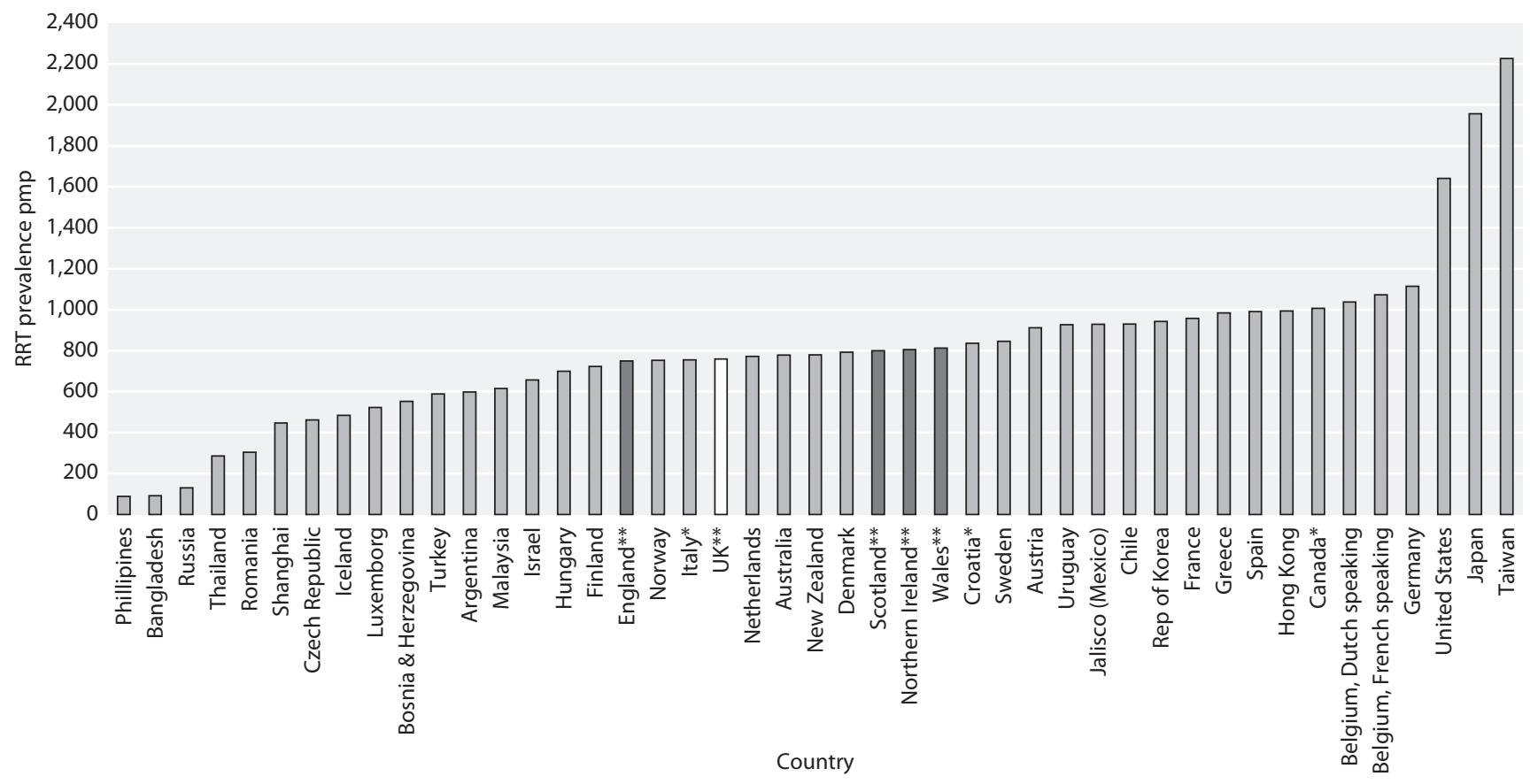

Fig. 14.3. Prevalence of RRT by country

*2005 data

**2007 data

24\% in Northern Ireland, 20\% in England and 17\% in Scotland.

\section{Prevalence of $R R T$}

The RRT prevalence rate of $760 \mathrm{pmp}$ in the UK was 23rd of the 41 countries reporting prevalence data to the USRDS (figure 14.3). Within the UK, rates were lowest in England at $750 \mathrm{pmp}$ and highest in Wales at $812 \mathrm{pmp}$. Rates of home haemodialysis use were comparable between UK countries at $1.5-2.0 \%$ of the prevalent dialysis population. Australia and New Zealand continued to achieve home HD rates as high as $10-16 \%$ (figure 14.4).

\section{Transplantation}

Considering the number of renal transplants (combined deceased and live donor) performed in each country each year, the UK rate of $36 \mathrm{pmp}$ placed it 15th of 38 countries, considerably lower than Spain, Jalisco (Mexico) and the USA where rates varied between 50$60 \mathrm{pmp}$ (figure 14.5). Transplantation rates in all the four countries have increased compared with the last report with England having the highest transplantation rate at $37 \mathrm{pmp}$, Wales $35 \mathrm{pmp}$, Scotland $31 \mathrm{pmp}$ and Northern Ireland $22 \mathrm{pmp}$.

\section{Attainment of standards}

The completeness of data for BP, HbAlc and total cholesterol is included in Tables 14.2 to 14.4. Completeness for HD and PD data from England, Wales and Northern Ireland for cholesterol was more than $80 \%$; levels of data completeness were lower for post dialysis blood pressure and HbAlc.

Within the UK, the percentage of prevalent RRT patients with post-HD blood pressure $<130 / 80 \mathrm{mmHg}$ was $28 \%$ in England, $27 \%$ in Northern Ireland and $26 \%$ in Wales (table 14.2). The only national or regional renal registry reporting blood pressure (BP) in accordance with KDOQI standards was the Finnish Renal Registry which reported a similar figure with $28 \%$ of dialysis patients attaining a BP of $<130 / 85$.

Adequate diabetic control (defined as $\mathrm{HbAlc}<7 \%$ ) in the prevalent HD patients, varied from 39\% in Northern Ireland to 51\% in England (table 14.3), although the completeness of data was $97 \%$ in Northern Ireland compared with $72 \%$ in England. Rates of attainment of the HbAlc standard appeared lower in Finland at 35\%, who had a similar high rate of data completeness to Northern Ireland. The lower rates of data completeness for HbAlc in many UK centres do not indicate that $\mathrm{HbAlc}$ was not being measured, as the control of diabetic 


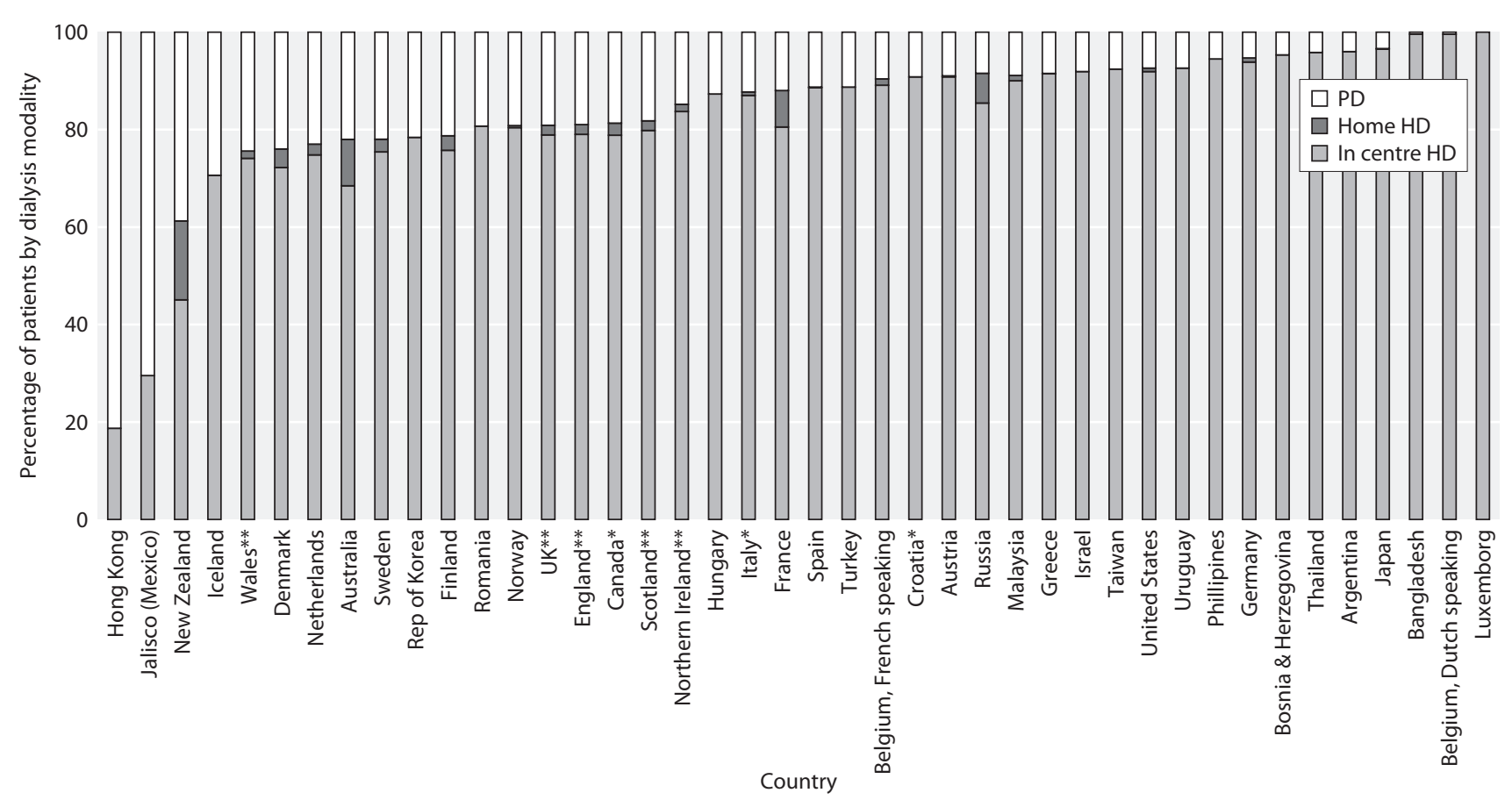

Fig. 14.4. Percentage of prevalent dialysis population by dialysis modality *2005 data **2007 data

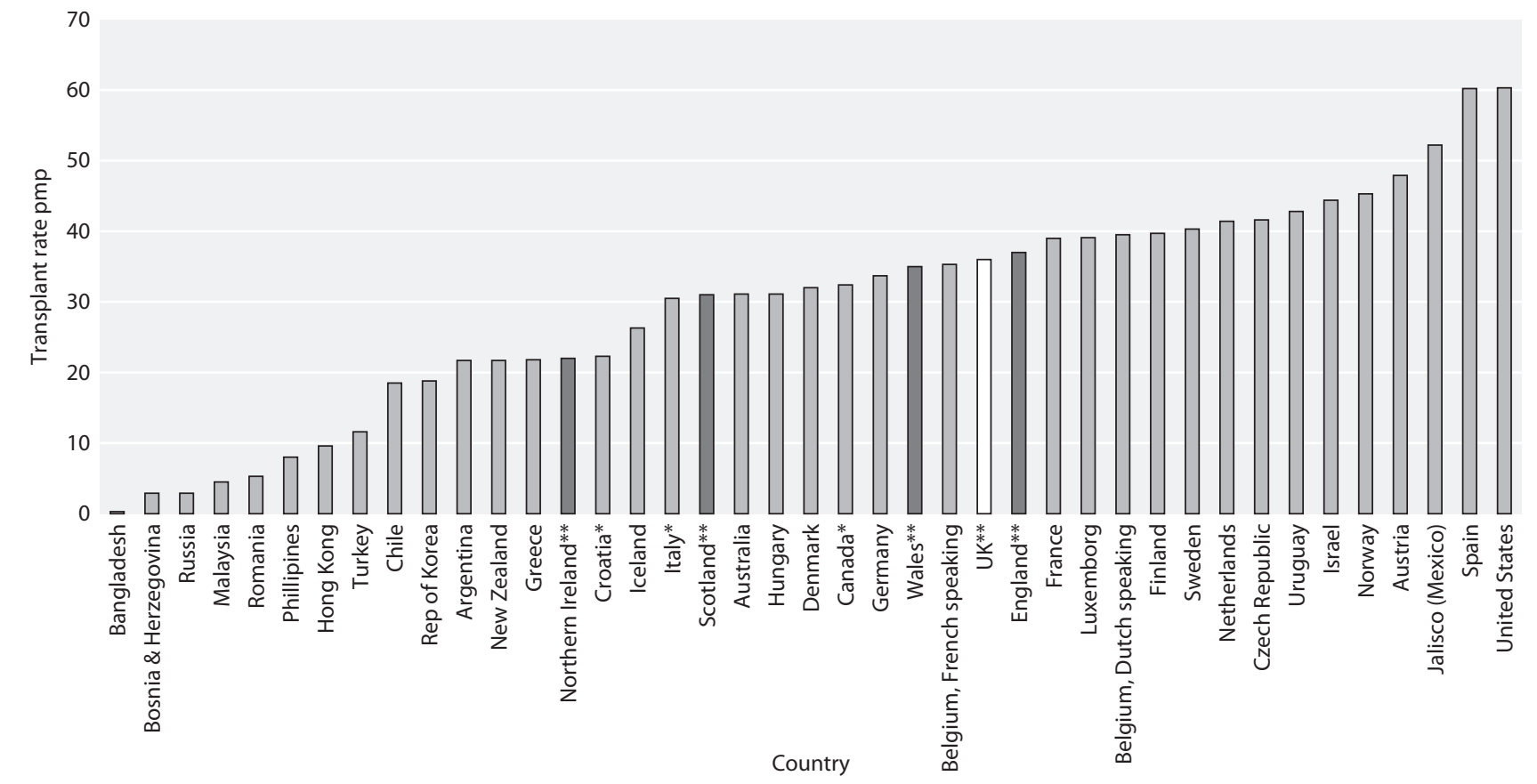

Fig. 14.5. Renal transplant incidence rate by country (pmp) *2005 
Table 14.2. Percentage of data completeness and achievement of post dialysis $\mathrm{BP}<130 / 80 \mathrm{mmHg}$

\begin{tabular}{|c|c|c|c|c|c|c|c|}
\hline & \multicolumn{2}{|c|}{ England } & \multicolumn{2}{|c|}{$\mathrm{N}$ Ireland } & \multicolumn{2}{|c|}{ Wales } & \multirow[b]{2}{*}{ Finland dialysis } \\
\hline & HD & $\mathrm{PD}$ & $\mathrm{HD}$ & PD & HD & $\mathrm{PD}$ & \\
\hline Completeness \% & 57 & 45 & 91 & 21 & 42 & 19 & 98 \\
\hline$\% \mathrm{BP}<130 / 80$ & 28 & 30 & 27 & 50 & 26 & 21 & 28 \\
\hline
\end{tabular}

*All dialysis patients; cut-off $130 / 85 \mathrm{mmHg}$

Table 14.3. Percentage of data completeness ( $\%$ of patients with primary renal disease of diabetes with HbAlc data) and achievement of $\mathrm{HbAlc}<7 \%$

\begin{tabular}{|c|c|c|c|c|c|c|c|}
\hline & \multicolumn{2}{|c|}{ England } & \multicolumn{2}{|c|}{$\mathrm{N}$ Ireland } & \multicolumn{2}{|c|}{ Wales } & \multirow[b]{2}{*}{ Finland dialysis } \\
\hline & $\mathrm{HD}$ & $\mathrm{PD}$ & $\mathrm{HD}$ & $\mathrm{PD}$ & HD & PD & \\
\hline Completeness \% & 72 & 74 & 97 & 78 & 26 & 36 & 98 \\
\hline$\% \mathrm{HbA} 1 \mathrm{c}<7 \%$ & 51 & 36 & 39 & 21 & 46 & 55 & 35 \\
\hline
\end{tabular}

Table 14.4. Percentage of data completeness and total cholesterol $<5 \mathrm{mmol} / \mathrm{L}$

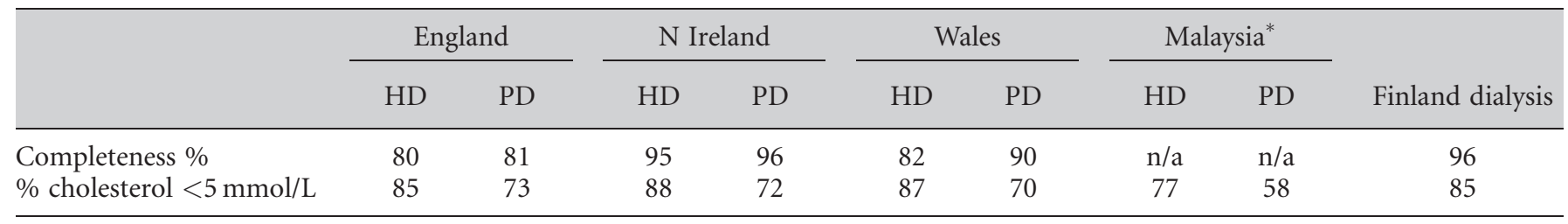

${ }^{*}<5.3 \mathrm{mmol} / \mathrm{L}$

care is often monitored by general practitioners with results not being visible in the secondary care setting.

Generally PD patients achieved poorer control of diabetes than patients on HD. This was probably due to the additional glucose load from the PD fluid.

Information regarding the use of cardio protective medication and smoking among prevalent RRT patients were unavailable from other renal registries. In the USA, $72 \%$ of diabetic patients on dialysis were treated with ACE-I or angiotensin receptor blockers and HMG-Co A reductase inhibitors were prescribed in $51 \%$ of such patients.

\section{Discussion}

In 2007, the incidence of RRT in the UK was $111 \mathrm{pmp}$ using the day 0 definition and after making the adjustment for paediatric patients. This RRT incidence rate placed the UK 34 th out of 43 countries reporting to the USRDS in 2006. The overall incidence for the UK masked a higher incidence rate in Wales of $142 \mathrm{pmp}$.
Taiwan had the highest incidence and prevalence of RRT of the 43 countries reporting data to the USRDS at 418 pmp.

The percentage of incident RRT patients with diabetes recorded as the primary renal diagnosis remained relatively low in the UK at 20\%, compared with $44-58 \%$ in the United States, Jalisco (Mexico) and Malaysia. This overall UK rate again masked considerable variation between nations with 34\% of incident RRT patients in Wales being listed as having diabetes as the primary renal diagnosis. While this may reflect a variation in interpretation of whether diabetes was a comorbidity or the primary renal diagnosis, the rate of diabetes mellitus does appear higher in Wales when data from the Welsh Health Survey [12] were compared with data from the Health Survey for England [13]; in Wales, 6\% of respondents reported receiving treatment for diabetes mellitus whereas in England 4.3\% of males and 3.4\% of females reported that they had been given a diagnosis of diabetes by their doctor.

The 2007 RRT prevalence rate of 760 pmp placed the UK 23 rd out of the 41 countries reporting to the USRDS. PD utilisation amongst prevalent dialysis patients varied 
around the world from $0 \%$ in Luxembourg to $81 \%$ in Hong Kong. Australia and New Zealand lead the world with regard to home haemodialysis with rates of $9-16 \%$. Despite National Institute for Health and Clinical Excellence guidance promoting home haemodialysis in the UK [14], the percentage of patients on this modality remained at 1.5 to $2 \%$ of the prevalent dialysis population.

The renal transplantation rate in the UK continued to improve, with increasing rates of living kidney and nonheart beating donation. However, the 36 new transplants per million of the population performed in 2007 in the UK remained considerably lower than in the United States (60 pmp), Spain (60 pmp) and Jalisco (Mexico) (52 pmp).

There was limited reporting of attainment of CV risk management standards by renal registries around the world. Further, where data were reported there was little consistency in definition adopted to enable international comparisons; the Finnish Registry reported $\mathrm{HbAlc}$ data according to the KDOQI standards and only the Finnish and Malaysian Registries reported attainment of cholesterol targets that were comparable (if not KDOQI consistent).

The percentage of prevalent dialysis patients in England, Wales and Northern Ireland achieving the KDOQI post dialysis BP standard $(<130 / 80 \mathrm{mmHg})$ was low at $25-28 \%$, but these rates were comparable to those reported by the Finish Renal Registry (28\% for dialysis patients). Unfortunately the Malaysian Renal Registry reported attainment of pre dialysis blood pressure $<140 / 90 \mathrm{mmHg}$ ( $25.5 \%$ for HD and $53 \%$ for PD) and rates were therefore difficult to compare.

Rates of attainment of the diabetes mellitus HbAlc standard appeared much higher in the UK than in Finland, although it was difficult to know how to inter- pret this given the very different data completeness rates.

The USRDS collected details of a number of CV medication in patients with diabetes on RRT, but these data were not available from other registries. Reports from the Dialysis Outcomes and Practice Patterns Study have demonstrated significant variations (8$41 \%)$ in aspirin prescribing between countries [15]. Work is underway at the UKRR to electronically capture prescribed medication on renal IT systems used in dialysis centres, but to date no routinely available information exists on prescription rates for aspirin, beta blockers, HMG-Co A reductase inhibitors or ACE-inhibitors in patients on RRT in the UK.

Another hugely important CV risk is smoking status; this was recorded by many renal registries but often only at initiation of RRT and with no quantification of life-time exposure.

Despite the high CV morbidity associated with RRT, few renal registries routinely report data on CV risk management. Part of the explanation for this is likely to be the labour-intensive, paper-based reporting employed by many registries. Further, where data were reported there was little agreement in what represented quality of care, making direct comparison difficult. Uncertainty arising from apparently negative clinical trials of HMG-Co A reductase inhibitors [16] and paradoxical associations between BP and mortality [17] - reverse epidemiology - is likely to be contributing to this lack of agreement. If an evidence-based consensus could be reached on which quality markers for CV risk management should be reported by renal registries, international benchmarking of this important aspect of care may be achievable.

\section{Conflict of interest: none}

\section{References}

1 Caskey FJ, Schober-Halstenberg HJ, Roderick PJ, et al. Exploring the differences in epidemiology of treated ESRD between Germany and England and Wales. Am J Kidney Dis 2006;47(3):445.

2 Stewart JH, McCredie MR, Williams SM, et al. The enigma of hypertensive ESRD: observations on incidence and trends in 18 European, Canadian, and Asian-Pacific populations, 1998 to 2002. Am J Kidney Dis 2006;48(2):183.

3 De Vecchi AF, Dratwa M, Wiedemann ME. Healthcare systems and end-stage renal disease (ESRD) therapies - an international review: costs and reimbursement/funding of ESRD therapies. Nephrol. Dial. Transplant. 1999;14(suppl_6):31.

4 Menon V, Gul A, Sarnak MJ. Cardiovascular risk factors in chronic kidney disease. Kidney Int 2005;68(4):1413.

5 Foley RN, Parfrey PS, Sarnak MJ. Clinical epidemiology of cardiovascular disease in chronic renal disease. Am J Kidney Dis 1998;32(5 Suppl 3):S112.

6 van Dijk PCW, Jager KJ, de Charro F, et al. Renal replacement therapy in Europe: the results of a collaborative effort by the ERAEDTA registry and six national or regional registries. Nephrol. Dial. Transplant. 2001; 16(6):1120.

7 Ansell D, Feest TG. Chapter 11: Factors which may Influence Cardiovascular Disease Blood Pressure and Serum Cholesterol. The Eighth Annual Report. Bristol: UK Renal Registry, 2005.

8 U.S. Renal Data System. USRDS 2008 Annual Data Report: Atlas of End-Stage Renal Disease in the United States: National Institute of Diabetes and Digestive and Kidney Diseases, 2008.

$9 \mathrm{~K} / \mathrm{DOQI}$ clinical practice guidelines for management of dyslipidemias in patients with 
kidney disease. Am J Kidney Dis 2003;41(4 Suppl 3):I.

$10 \mathrm{~K} / \mathrm{DOQI}$ clinical practice guidelines on hypertension and antihypertensive agents in chronic kidney disease. Am J Kidney Dis 2004;43(5 Suppl 1):S1.

11 KDOQI Clinical Practice Guidelines and Clinical Practice Recommendations for Diabetes and Chronic Kidney Disease. Am J Kidney Dis 2007;49(2 Suppl 2):S12.

12 Chapter 3: Health status, Illnesses and Other Comorbid Conditions. In: Dolman R, Kingdon A, Roberts C, eds. Welsh Health Survey. Cardiff: Statistics for Wales, 2007.
13 Volume 2: Risk factors for cardiovascular disease. In: Sproston K, Primatesta P, eds. Health Survey for England 2003. London: National Centre for Social Research and Department of Epidemiology and Public Health at the Royal Free and University College Medical School, 2004.

14 Guidance on home compared with hospital haemodialysis for patients with end-stage renal failure. London: National Institute of Clinical Excellence, 2002.

15 Jean Ât, Jennifer LB-G, Luis P, et al. Aspirin Prescription and Outcomes in Hemodialysis Patients: The Dialysis Outcomes and Practice
Patterns Study (DOPPS). American journal of kidney diseases: the official journal of the National Kidney Foundation 2007;50(4):602. 16 Wanner C, Krane V, Marz W, et al. Randomized controlled trial on the efficacy and safety of atorvastatin in patients with type 2 diabetes on hemodialysis (4D study): demographic and baseline characteristics. Kidney Blood Press Res 2004;27(4):259.

17 Li Z, Lacson E, Jr., Lowrie EG, et al. The epidemiology of systolic blood pressure and death risk in hemodialysis patients. Am J Kidney Dis 2006;48(4):606. 